\title{
Physiological effects of roflumilast at rest and during exercise in COPD
}

\author{
Denis E. O’Donnell*, Dirk Bredenbröker", Manja Brose* and Katherine A. Webb*
}

ABSTRACT: The purpose of this study was to investigate the effects of $500 \mu \mathrm{g}$ roflumilast, taken once daily for 12 weeks, on airway physiology during rest and exercise in patients with moderateto-severe chronic obstructive pulmonary disease.

This randomised, double-blind, placebo-controlled, parallel-group study was conducted in 250 patients with a post-bronchodilator forced expiratory volume in $1 \mathrm{~s}$ (FEV 1 ) of $30-80 \%$ predicted and a functional residual capacity of $\geqslant 120 \%$ pred. Pre- and post-bronchodilator spirometry and body plethysmography, and pre-bronchodilator constant work rate cycle exercise at $75 \%$ of peak work rate were evaluated. Exercise measurements included ventilation, breathing pattern, inspiratory capacity (IC) and arterial oxygen saturation measured by pulse oximetry $\left(\mathrm{Sp}, \mathrm{O}_{2}\right)$.

Compared with placebo, 12 weeks of treatment with roflumilast was associated with: small but progressive increases in pre- and post-bronchodilator FEV 1 and FEV 1 /forced vital capacity; small decreases in specific airway resistance; and no significant changes in resting vital capacity, IC or measurements of lung hyperinflation. There was no treatment effect on exercise endurance time. At a standardised exercise time after roflumilast, compared with placebo, IC increased by $0.12 \mathrm{~L}(p=0.008)$ and $\mathrm{Sp}, \mathrm{O}_{2}$ increased by $0.7 \%(p=0.020)$; peak ventilation increased by $1.9 \mathrm{~L} \cdot \mathrm{min}^{-1}(p=0.014)$.

Roflumilast treatment was associated with progressive improvement of airway function but not lung hyperinflation. Newly described non-bronchodilator effects of roflumilast included small but consistent improvements in air trapping and $\mathrm{Sp}, \mathrm{O}_{2}$ during exercise.

KEYWORDS: Anti-inflammatory, chronic obstructive pulmonary disease, exercise, phosphodiesterase-4 inhibitor

$\mathbf{R}$ oflumilast, a phosphodiesterase (PDE)4 inhibitor, is a novel oral anti-inflammatory agent that, in clinical studies, has been shown to reduce exacerbations in patients with chronic obstructive pulmonary disease (COPD) who have symptoms of chronic bronchitis and a history of exacerbations [1-3]. Studies have also confirmed that roflumilast treatment is associated with small improvements in pre- and post-bronchodilator forced expiratory volume in $1 \mathrm{~s}$ (FEV1) $[1,2,4,5]$. At present, the nature and precise physiological mechanisms of improved airway function are unknown, and are the main focus of the current study.

The relatively slow time course of the increase in FEV1 following the onset of roflumilast therapy is consistent with an anti-inflammatory action at the airway mucosa level. Indeed, similar small and delayed improvements in spirometry have been reported following treatment with inhaled corticosteroid monotherapy in COPD [6, 7]. PDE4 inhibitors, such as roflumilast, have no direct bronchodilatory effects on airway smooth muscle [8]. Therefore, it is reasonable to postulate that the gradual improvement in airway conductance is related to reduced mucosal oedema or mucoinflammatory exudates, but this requires experimental verification.

No consensus currently exists as to the optimal methodology to assess the effect of anti-inflammatory therapies on airway function in COPD. In moderate-to-severe COPD, bronchodilator therapy is associated with consistent reductions in lung hyperinflation with concurrent increases in inspiratory capacity (IC), during both rest and exercise [9, 10]. However, the impact of roflumilast on lung volume components during rest and exercise has not been previously studied and is likely to be different from the effects of bronchodilators. Moreover, based on a previous study in asthma, it is possible that additional physiological effects, such as improved arterial oxygenation, may be present following anti-inflammatory treatment in COPD, independent of improved respiratory mechanics [11].

The objective of the current study was to examine the effect of roflumilast on spirometry, plethysmographic measurements of airway resistance
AFFILIATIONS

*Respiratory Investigation Unit, Queen's University and Kingston General Hospital, Kingston, ON, Canada, and

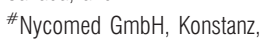
Germany.

CORRESPONDENCE

D.E. O'Donnell

Respiratory Investigation Unit

Queen's University and Kingston

General Hospital

102 Stuart Street

Kingston

ON

K7L 2V6

Canada

E-mail: odonnell@queensu.ca

Received:

June 062011

Accepted after revision:

Aug 222011

First published online:

Sept 292011 
and lung volume, and physiological and perceptual responses to constant work rate (CWR) cycle exercise in patients with moderate-to-severe COPD. Therefore, we conducted a 12week, multicentre, randomised, double-blind, parallel-group study in patients with COPD who had resting lung hyperinflation. By examining the effects of roflumilast on operating lung volumes, breathing pattern and indices of pulmonary gas exchange during exercise, we hoped to gain new insights into the direct physiological consequences of suppression of airway inflammation in COPD.

\section{METHODS}

\section{Subjects}

Subjects were clinically stable patients $\geqslant 40$ yrs of age with a smoking history of $\geqslant 10$ pack-yrs and a $\geqslant 12$-month history of COPD [12]. Other inclusion criteria included: post-bronchodilator FEV1 30-80\% predicted, FEV1/forced vital capacity (FVC) $<0.7$ and plethysmographic functional residual capacity (FRC) $\geqslant 120 \%$ pred; and peak oxygen uptake $\left(V^{\prime} \mathrm{O}_{2}\right)<80 \%$ pred during incremental cycle exercise. Exclusion criteria included: a diagnosis of asthma or a lung disease other than COPD; $\alpha_{1}$-antitrypsin deficiency; participation in a pulmonary rehabilitation programme within 2 months; supplemental oxygen therapy; a COPD exacerbation or respiratory tract infection within 4 weeks; a concomitant disease that might interfere with the ability to exercise; or stopping incremental cycle exercise testing due to leg discomfort alone.

\section{Study design}

This was a randomised, double-blind, placebo-controlled, parallel-group study conducted between 2003 and 2005. A parallel-group design was used to avoid the potential carry over and sequence effects that may exist with the use of antiinflammatory medications. The 12-week treatment arms consisted of $500 \mu \mathrm{g}$ roflumilast (ROF) or placebo (PBO). The target enrolment was 230 subjects at 22 centres in Canada, France, Germany and Hungary. All centres received research ethics approval prior to participation.

After patient consent was obtained, subjects completed an initial screening visit (B0), which included a medical history and physical examination followed by pulmonary function tests (pre- and post-bronchodilator), and a symptom-limited incremental cycle exercise test. Eligible subjects then began a 2-3-week baseline period consisting of two familiarisation visits during which a symptom-limited CWR cycle exercise test was performed at $75 \%$ of the maximum incremental work rate (Wmax). If CWR endurance time was not reproducible within 2 min or $10 \%$ at these visits, then a third visit was performed. If reproducibility was not achieved at this visit, the patient was not randomised. During the baseline period, patients received single-blind PBO medication. If randomisation criteria were met, subjects were randomised to blinded study medication and completed pretreatment testing $(\mathrm{T} 0)$ : pre-bronchodilator pulmonary function and CWR exercise tests were performed, $400 \mu \mathrm{g}$ salbutamol was administered after a 30-min rest period and post-bronchodilator pulmonary function tests were performed $30 \mathrm{~min}$ later. An identical visit was conducted after 12 weeks of treatment (T12). Visits conducted after 4 weeks (T4) and 8 weeks (T8) of treatment included pre-bronchodilator testing only. If a randomised subject discontinued the study prematurely, then the T12 assessments were completed. The end-point visit (Tlast) was defined as visit T12 or the last visit conducted in the case of early termination. All pre-bronchodilator testing began between 08:00 and 11:00 h.

\section{Treatments}

Study medication (ROF or $\mathrm{PBO}$ ) was taken once daily in tablet form after breakfast and with $\geqslant 200 \mathrm{~mL}$ of fluid. A 1:1 randomisation ratio was used, with stratification according to smoking status (i.e. current smokers or ex-smokers). Inhaled longacting $\beta_{2}$-agonists, theophyllines and systemic corticosteroids were not allowed throughout the study and were withdrawn at visit B0; long-acting anticholinergics were not permitted within the 4 weeks before visit $\mathrm{B} 0$, but prior tiotropium bromide could be switched to a regular dose of ipratropium bromide at that time. Inhaled corticosteroids (ICS) were permitted throughout the study if taken at a constant dosage $(\leqslant 2,000 \mu \mathrm{g}$ beclomethasone dipropionate or equivalent) for $\geqslant 3$ months prior to the study. Inhaled salbutamol as needed and ipratropium bromide in stable regular dosages were permitted throughout the study but were withheld $\geqslant 4$ and $\geqslant 6 \mathrm{~h}$ prior to study visits, respectively.

\section{Procedures}

Use of medications and safety variables were evaluated at each visit. Activity-related dyspnoea was assessed using the Baseline Dyspnoea Index or Transition Dyspnoea Index (TDI) [13]. Spirometry and body plethysmography were conducted according to recommendations [14, 15], and measurements were expressed relative to predicted normal values [16, 17]. Singlebreath diffusing capacity of the lung for carbon monoxide $(D \mathrm{~L}, \mathrm{CO})$ [18] was measured at visits $\mathrm{B} 0$ and T12 only.

Symptom-limited exercise tests were conducted on electronically braked cycle ergometers using approved cardiopulmonary exercise testing systems with integrated IC measurements. The incremental test consisted of a steady-state resting period $\geqslant 3 \mathrm{~min}, 1 \mathrm{~min}$ of unloaded pedalling and subsequent stepwise increases in work rate of $10 \mathrm{~W} \cdot \mathrm{min}^{-1} ; W_{\max }$ was defined as the highest work rate that the subject could maintain for $\geqslant 30 \mathrm{~s}$. CWR exercise tests were performed in a similar manner, but the work rate was adjusted to $75 \%$ of $W_{\max }$; exercise endurance time was defined as the duration of loaded pedalling. Measurements were collected while subjects breathed through a rubber mouthpiece with a nose clip and included: breath-by-breath cardiopulmonary and breathing pattern parameters; arterial oxygen saturation measured by pulse oximetry $\left(\mathrm{Sp}, \mathrm{O}_{2}\right)$; ECG; blood pressure; intensity of dyspnoea (breathing discomfort) and leg discomfort assessed using the modified 10-point Borg scale [19] at rest, at 1min intervals during exercise and at end-exercise; IC manoeuvres performed at rest (three acceptable measurements), singly at 2min intervals during exercise and again immediately upon signalling the need to stop exercise; and the reason(s) for stopping exercise. Measurements were averaged in 30-s intervals throughout exercise: isotime was defined as the highest equivalent exercise time achieved during all CWR tests performed by a given subject, rounded down to the nearest whole minute; and peak was the last 30-s of loaded pedalling. Peak $V^{\prime} \mathrm{O}_{2}$ was expressed as a percentage of the predicted normal value [20].

\section{Statistical analysis}

A sample size of 115 subjects per treatment arm ensured a power of $90 \%$ to detect a significant treatment difference in the primary 
variable pre-bronchodilator exercise endurance time under the following assumptions: two-sided $\alpha=0.05$; normal distribution; improvement in ROF compared with $\mathrm{PBO}$ in group means of $100 \mathrm{~s}$; and common standard deviation of $230 \mathrm{~s}$ (effect size 0.435). With a common standard deviation of $269 \mathrm{~s}$ (effect size 0.372 ), a power of $80 \%$ results when evaluating 115 subjects per treatment arm.

The primary analysis was conducted on the intent-to-treat population. Treatment differences were analysed as changes from T0 to Tlast and presented as least square mean $\pm \mathrm{SE}$; two-sided p-values are reported. An ANCOVA was performed to test the hypothesis for the treatment difference in the primary variable. In addition to the treatment, the following factors and covariables (all fixed) were included in the model: value at visit T0, age, sex, smoking status, country, and ICS pretreatment. No interaction term was included in the primary model. Similarly, the ANCOVA was used to analyse key secondary variables, i.e. pre- and post-bronchodilator spirometry, plethysmographic lung volume and airway resistance measurements, pre-bronchodilator dyspnoea intensity at isotime during exercise, pre-bronchodilator dynamic IC at isotime

\section{TABLE 1 Baseline characteristics of the study population}

ROF

\section{Subjects $\mathbf{n}$}

Males \%

Age yrs

Height $\mathrm{cm}$

Body mass index $\mathrm{kg} \cdot \mathrm{m}^{-2}$

Cigarette smoking history pack-yrs ${ }^{\#}$

Current smokers \%

Prior LABA ${ }^{\text {T, }} \%$

Prior tiotropium ${ }^{\mathbf{s}} \%$

Prior theophyllines ${ }^{+} \%$

Concomitant ICS treatment \%

Concomitant ipratropium treatment \%

BDI focal score

Peak incremental $\mathrm{V}^{\prime} \mathrm{O}_{2} \%$ pred

Wmax W

GOLD stage \%

I, mild

II, moderate

III, severe

IV, very severe

Pulmonary function

Pre-bronchodilator

FEV 1 L (\% pred)

FEV $1 / F V C \%$

FEF25-75\% L.S ${ }^{-1}$ (\% pred)

IC L

SVC $L$ (\% pred)

TLC L (\% pred)

RV L (\% pred)

FRC $L$ (\% pred)

sRaw $\mathrm{KPa} \cdot \mathrm{s}$

$\mathrm{DL}, \mathrm{CO} \mathrm{mL} \cdot \mathrm{min}^{-1} \cdot \mathrm{mmHg}^{-1}$

Post-bronchodilator

FEV $1 \%$ pred

FEV $1 /$ FVC \%

$\triangle \mathrm{FEV} 1 \%$
127

73.2

$60 \pm 9$

$170 \pm 9$

$26.4 \pm 5.0$

$41 \pm 20$

52.0

31.5

3.1

29.1

40.2

40.9

$6.6 \pm 2.0$

$63 \pm 13$

$80 \pm 25$

0.8

54.3

44.1

0.8

PBO

123

83.7

$59 \pm 10$

$171 \pm 8$

$26.3 \pm 4.6$

$41 \pm 22$

53.7

28.5

2.4

20.3

33.3

39.0

$6.8 \pm 2.1$

$61 \pm 13$

$82 \pm 27$

1.6

47.2

46.3

4.9

$1.51 \pm 0.53(49 \pm 14)$ $48 \pm 11$

$0.74 \pm 0.51(21 \pm 13)$

$2.44 \pm 0.66$

$3.19 \pm 0.83(81 \pm 16)$

$7.73 \pm 1.26(120 \pm 19)$

$4.53 \pm 1.16(199 \pm 54)$

$5.31 \pm 1.11(159 \pm 34)$

$2.55 \pm 1.36$

$19.2 \pm 8.4$

$54 \pm 13$

$50 \pm 11$

$13 \pm 16$

Data are presented as mean $\pm \mathrm{SD}$, unless otherwise stated. Measurements were taken at the beginning of the baseline period (Bo). ROF: roflumilast; PBO: placebo; LABA: long-acting $\beta_{2}$-agonist; ICS: inhaled corticosteroid; $\mathrm{BDI}$ : Baseline Dyspnoea Index; $V^{\prime} \mathrm{O}_{2}$ : oxygen uptake; \% pred: \% predicted; Wmax: maximal incremental work rate; GOLD: Global Initiative for Chronic Obstructive Lung Disease; FEV1: forced expiratory volume in $1 \mathrm{~s}$; FVC: forced vital capacity; FEF25-75\%: forced expiratory flow at 25$75 \%$ of FVC; IC: inspiratory capacity; SVC: slow vital capacity; TLC: total lung capacity; RV: residual volume; FRC: functional residual capacity; sRaw: specific airway resistance; $D L, C O$ : diffusing capacity of the lung for carbon monoxide; $\Delta$ : change. ${ }^{\#}: 1$ pack-yr represents 20 cigarettes per day for 1 yr; ${ }^{\natural}$ : LABA alone or in combination with an ICS; ${ }^{+}$: withdrawn at $\mathrm{B} 0$; ${ }^{\text {s: }}$ withdrawn 4 weeks before Bo. 
during exercise, pre-bronchodilator metabolic and cardiopulmonary variables at isotime, and peak exercise.

\section{RESULTS}

\section{Subjects}

Characteristics of the study population are shown in table 1. Age, height, body mass index, sex, race (99\% Caucasian), smoking history, and use of prior and concomitant respiratory medications were balanced across treatment groups. Frequency of comorbidities and reported previous diseases was also similar across groups (data not shown). Subjects in both groups had moderateto-severe airflow obstruction, a similar distribution across Global Initiative for Chronic Obstructive Lung Disease (GOLD) stages, significant lung hyperinflation, a preserved mean $D \mathrm{~L}, \mathrm{CO}$ and a reduced peak incremental $V^{\prime} \mathrm{O}_{2}$.

Of the 250 randomised subjects, 16 from the ROF group and 12 from the PBO group discontinued prematurely: the main reasons were adverse events in 12 and nine subjects, with COPD exacerbations in four and four subjects from the ROF and PBO groups, respectively. Of those with adverse events leading to discontinuation, five subjects from the ROF group were assessed as likely or definitely related to study medication and were listed as follows: gastrointestinal disorder $(n=1)$; diarrhoea $(n=2)$; dizziness, diarrhoea, dry mouth, decreased appetite and weight loss $(n=1)$; and nausea, decreased appetite, fatigue and headache $(n=1)$. The most common treatment-emergent adverse events were (ROF and $\mathrm{PBO}$, respectively): diarrhoea $(n=13$ and $n=2)$, nasopharyngitis $(n=9$ and $n=8)$, COPD exacerbation $(n=8$ and $n=5)$, dizziness $(n=8$ and $n=2)$, headache $(n=7$ and $n=2)$, nausea $(n=5$ and 3$)$, anxiety $(n=5$ and $n=0)$ and weight loss $(n=5$ and $n=0$ ). Compliance to study medication was excellent, at $>97 \%$ in the baseline and treatment periods for both groups.

\section{Pulmonary function}

Pulmonary function responses to treatment are summarised in table 2. There were no significant treatment differences in pre- or post-bronchodilator static lung volumes, or in pre-bronchodilator DL,CO. After treatment with ROF, there were small within-group improvements in pre-bronchodilator FEV1, FEV1/FVC and specific airway resistance (sRaw) (fig. 1), and in post-bronchodilator FEV1/FVC and sRaw. At Tlast, the treatment difference with ROF was superior to that with $\mathrm{PBO}$ for pre-bronchodilator FEV1 (84 $\pm 31 \mathrm{~mL} ; \mathrm{p}=0.007)$, FEV1/FVC $(1.8 \pm 0.7 \% ; \mathrm{p}=0.009)$ and forced expiratory flow at 25-75\% of FVC (FEF25-75\%) $\left(0.062 \pm 0.029 \mathrm{~L} \cdot \mathrm{s}^{-1} ; \mathrm{p}=0.036\right)$, and for post-bronchodilator FEV1 $(75 \pm 34 \mathrm{~mL} ; \mathrm{p}=0.030), \mathrm{FEV} 1 / \mathrm{FVC}(1.4 \pm 0.6 \% ; \mathrm{p}=0.029), \mathrm{FEF} 25-75 \%$ $\left(0.075 \pm 0.030 \mathrm{~L} \cdot \mathrm{s}^{-1} ; \mathrm{p}=0.014\right)$ and sRaw $\left(-0.19 \pm 0.093 \mathrm{kPa} \cdot \mathrm{s}^{-1}\right.$; $\mathrm{p}=0.043)$.

\section{CWR exercise}

Data at isotime (ROF: $6.0 \pm 0.3 \mathrm{~min}$; PBO: $7.0 \pm 0.3 \mathrm{~min}$ ) and peak exercise are provided in table 3 . There were no significant treatment differences in symptom-limited exercise endurance time or in peak $V^{\prime} \mathrm{O}_{2}$ (table 3). Intensity ratings of dyspnoea and leg discomfort measured at rest and throughout exercise were also unchanged with treatment (fig. 2). The reasons for stopping exercise were similar across groups at To. The proportion of patients stopping due to dyspnoea decreased significantly after ROF $(57.5 \%$ at T0 versus $42.1 \%$ at Tlast; $\mathrm{p}<0.001)$ but not after PBO ( $57.7 \%$ versus $57.6 \% ; \mathrm{p}=1.0)$ : the difference between groups was significant at Tlast $(\mathrm{p}=0.020)$.

\begin{tabular}{|c|c|c|c|c|}
\hline \multirow[t]{3}{*}{ TABLE 2} & \multicolumn{4}{|c|}{$\begin{array}{l}\text { Pulmonary function measurements at the } \\
\text { beginning (To) and end (Tlast) of study treatment } \\
\text { in the intention-to-treat analysis }\end{array}$} \\
\hline & & \multirow[t]{2}{*}{ To } & \multicolumn{2}{|c|}{ Tlast } \\
\hline & & & ROF & PBO \\
\hline \multicolumn{5}{|c|}{ Pre-bronchodilator } \\
\hline FEV 1 L & & 1.50 & $1.56 \pm 0.03^{*, \#}$ & $1.48 \pm 0.03$ \\
\hline $\mathrm{FEV}_{1} / \mathrm{FVC} \%$ & & 48.7 & $50.0 \pm 0.57^{\star, \#}$ & $48.2 \pm 0.63$ \\
\hline FEF25-75\% L & & 0.73 & $0.75 \pm 0.03^{\#}$ & $0.68 \pm 0.03$ \\
\hline PEFR $L \cdot S^{-1}$ & & 3.91 & $3.88 \pm 0.07$ & $3.74 \pm 0.08^{*}$ \\
\hline FVC L & & 3.08 & $3.07 \pm 0.04$ & $3.02 \pm 0.05$ \\
\hline SVC L & & 3.24 & $3.18 \pm 0.05$ & $3.20 \pm 0.05$ \\
\hline$I C L$ & & 2.39 & $2.34 \pm 0.04$ & $2.38 \pm 0.04$ \\
\hline TLC L & & 7.46 & $7.40 \pm 0.05$ & $7.41 \pm 0.06$ \\
\hline FRC L & & 5.09 & $5.08 \pm 0.05$ & $5.03 \pm 0.05$ \\
\hline $\mathrm{RV} L$ & & 4.24 & $4.18 \pm 0.07$ & $4.19 \pm 0.08$ \\
\hline $\mathrm{sRaw} \mathrm{kPa} \cdot \mathrm{s}$ & & 2.36 & $2.17 \pm 0.09^{*}$ & $2.34 \pm 0.10$ \\
\hline$D \mathrm{~L}, \mathrm{CO} \mathrm{mL} \cdot \mathrm{m}$ & $\mathrm{in}^{-1} \cdot \mathrm{mmHg}^{-1}$ & 18.8 & $18.5 \pm 0.44$ & $18.7 \pm 0.47$ \\
\hline$D \mathrm{~L}, \mathrm{CO} / \mathrm{VA} \mathrm{mL}$ & $\cdot \mathrm{min}^{-1} \cdot \mathrm{mmHg}^{-1} \cdot \mathrm{L}^{-1}$ & 3.18 & $3.16 \pm 0.07$ & $3.24 \pm 0.07$ \\
\hline \multicolumn{5}{|c|}{ Post-bronchodilator } \\
\hline FEV 1 L & & 1.65 & $1.68 \pm 0.03^{\#}$ & $1.61 \pm 0.03$ \\
\hline $\mathrm{FEV}_{1} / \mathrm{FVC} \%$ & & 49.5 & $50.7 \pm 0.53^{*, \#}$ & $49.3 \pm 0.60$ \\
\hline FEF25-75\% L & & 0.81 & $0.81 \pm 0.03^{\#}$ & $0.74 \pm 0.03^{\star}$ \\
\hline PEFR L.S ${ }^{-1}$ & & 4.30 & $4.28 \pm 0.07$ & $4.13 \pm 0.08^{*}$ \\
\hline FVC L & & 3.35 & $3.33 \pm 0.04$ & $3.29 \pm 0.04$ \\
\hline SVC L & & 3.51 & $3.50 \pm 0.04$ & $3.50 \pm 0.04$ \\
\hline$I C L$ & & 2.60 & $2.55 \pm 0.04$ & $2.57 \pm 0.05$ \\
\hline TLC L & & 7.44 & $7.45 \pm 0.06$ & $7.42 \pm 0.06$ \\
\hline FRC L & & 4.82 & $4.88 \pm 0.05$ & $4.81 \pm 0.05$ \\
\hline$R V L$ & & 3.89 & $3.93 \pm 0.06$ & $3.92 \pm 0.07$ \\
\hline $\mathrm{sRaw} \mathrm{kPa} \cdot \mathrm{s}$ & & 1.81 & $1.65 \pm 0.08^{\star, \#}$ & $1.84 \pm 0.08$ \\
\hline
\end{tabular}

Data are presented as least square mean \pm SE. ROF: roflumilast; PBO: placebo; FEV1: forced expiratory volume in $1 \mathrm{~s}$; FVC: forced vital capacity; FEF25-75\%: forced expiratory flow at $25-75 \%$ of FVC; PEFR: peak expiratory flow rate; SVC: slow vital capacity; IC: inspiratory capacity; TLC: total lung capacity; FRC: functional residual capacity; RV: residual volume; sRaw: specific airway resistance; $D L, C O$ : diffusing capacity of the lung for carbon monoxide; VA: alveolar volume. *: $p<0.05$ for Tlast versus To; ${ }^{*}: \mathrm{p}<0.05$ for ROF versus PBO treatment effect (Tlast minus To).

After ROF, compared with $\mathrm{PBO}$, there were small increases in ventilation during exercise $\left(1.9 \pm 0.7 \mathrm{~L} \cdot \mathrm{min}^{-1}\right.$ at peak; $\left.\mathrm{p}=0.014\right)$, which appeared to result from increases in respiratory frequency $(f \mathrm{R})$, with no change in tidal volume $(V \mathrm{~T})$ (fig. 3). Although there were no significant between-group treatment differences in $f R$ throughout exercise, significant increases were found at all paired exercise time-points within the ROF group at Tlast compared with To (i.e. $1.6 \pm 0.4$ breaths $\cdot \mathrm{min}^{-1}$ at peak; $\mathrm{p}<0.001$ ).

There were no significant between-treatment differences for dynamic IC measured pre-exercise or at peak exercise, but the treatment difference reached statistical significance at $2 \mathrm{~min}$ $(0.12 \pm 0.04 \mathrm{~L} ; \mathrm{p}=0.007)$ and at isotime $(0.12 \pm 0.05 \mathrm{~L} ; \mathrm{p}=0.008)$ during exercise. There were no significant within-group differences in exercise IC measurements from To to Tlast in the ROF group; however, dynamic IC at rest $(-0.11 \pm 0.04 \mathrm{~L} ; \mathrm{p}=0.008)$ and 

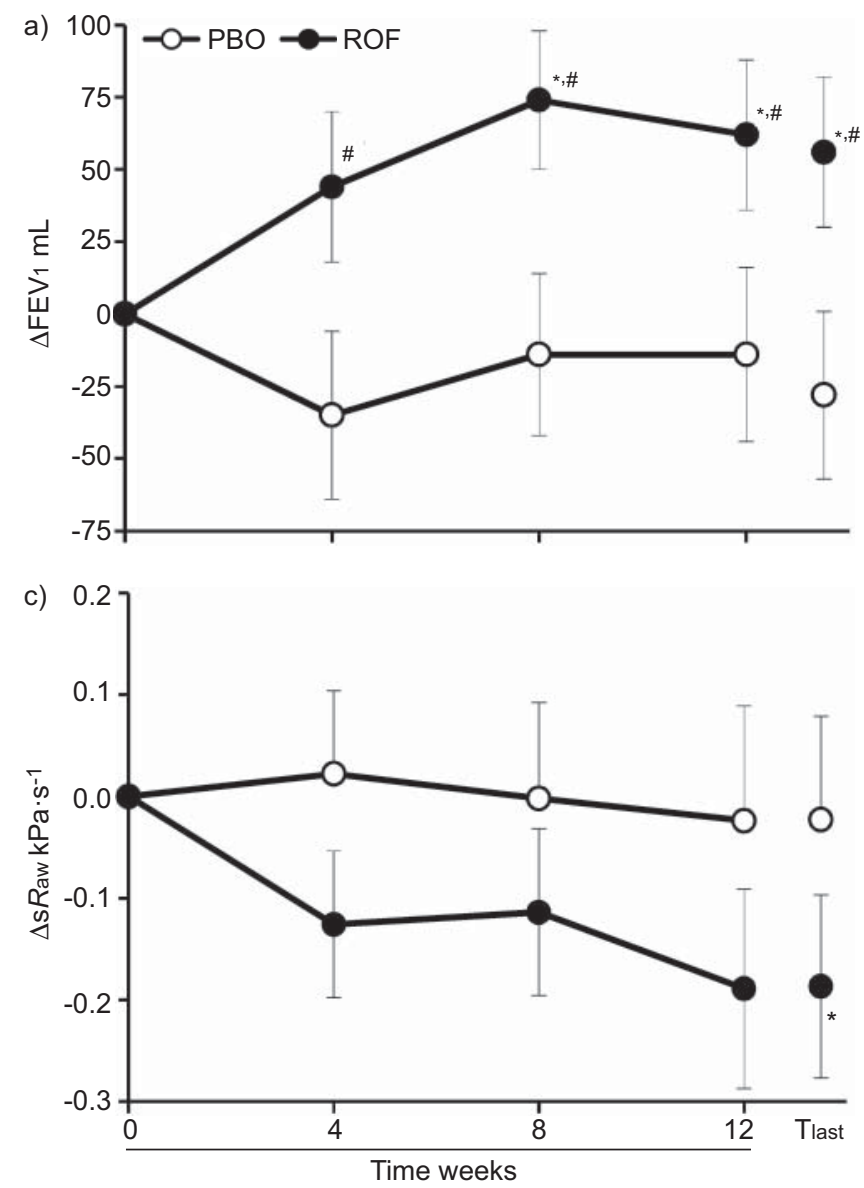
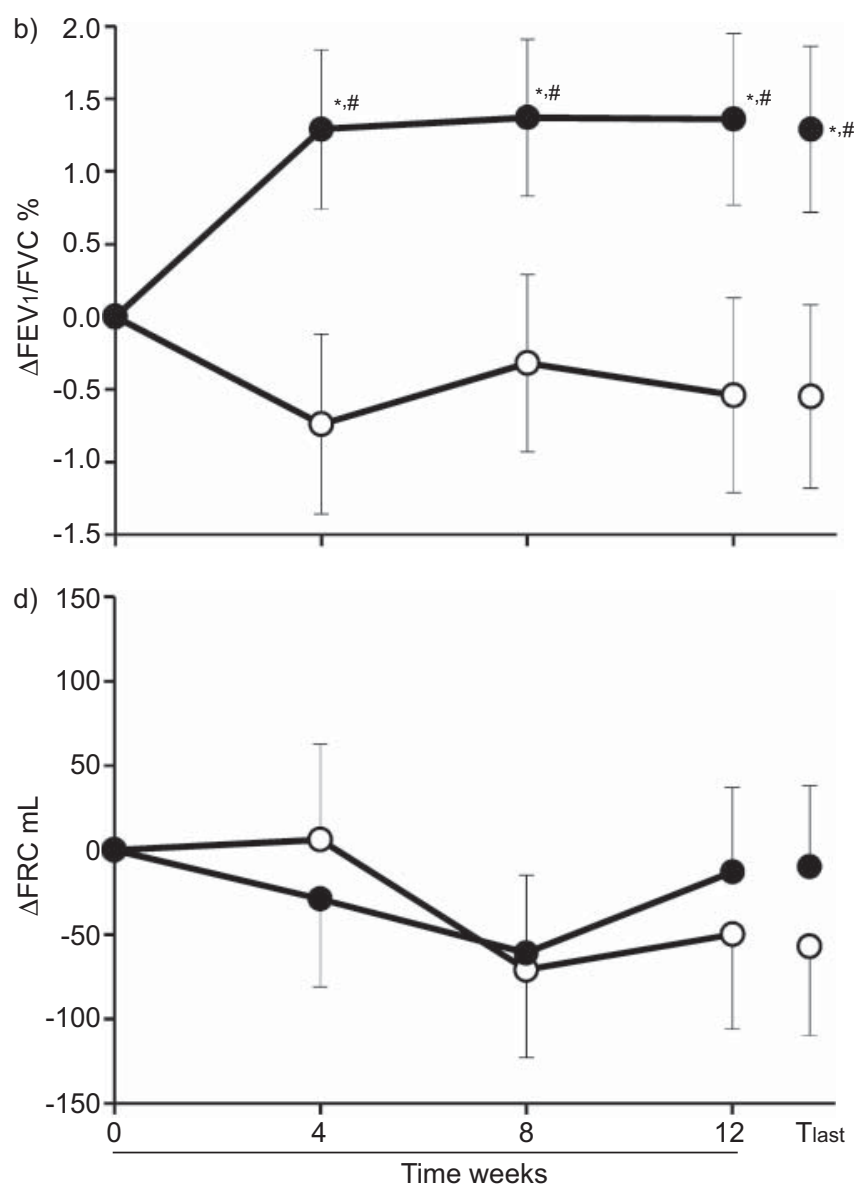

FIGURE 1. Change in $(\Delta)$ a) forced expiratory volume in $1 \mathrm{~s}$ (FEV1), b) FEV1/forced vital capacity (FVC), c) specific airway resistance (sRaw) and d) functional residual capacity (FRC) are shown during treatment with roflumilast (ROF) and placebo (PBO). Data are presented as least square mean \pm SE. Tlast: end-point visit. *: $p<0.05$ for within-treatment difference from pre-treatment testing visit; ${ }^{*}: \mathrm{p}<0.05$ for between-group treatment difference.

throughout exercise $(-0.16 \pm 0.05 \mathrm{~mL}$ at peak; $\mathrm{p}=0.001)$ decreased significantly over the course of treatment within the PBO group.

Although there was no significant treatment difference in resting $S p, \mathrm{O}_{2}(0.4 \pm 0.2 \% ; \mathrm{p}=0.067)$, there were small significant $(\mathrm{p}<0.05)$ treatment differences throughout exercise in favour of ROF, i.e. less desaturation during exercise after ROF compared with $\mathrm{PBO}$ (table 3 and fig. 4). Based on isotime exercise data, this difference appeared to be progressive over the 12-week treatment period (fig. 4).

\section{Activity-related dyspnoea}

The TDI focal score improved more with ROF than PBO after 8 weeks (treatment difference $0.81 \pm 0.35$ units; $p=0.021$ ) and 12 weeks $(0.84 \pm 0.38$ units; $\mathrm{p}=0.029)$ of treatment; at Tlast, the treatment difference was $0.68 \pm 0.38(\mathrm{p}=0.078)$. Significant withintreatment improvements for ROF at Tlast were found for the TDI focal score $(0.89 \pm 0.31$ units; $p=0.004)$ and each of its components, whereas no significant differences were found within the PBO group.

\section{Pre-specified subgroup analyses}

There were no significant treatment-by-country, treatmentby-smoking status or treatment-by-ICS pre-treatment interactions found for the primary or key secondary outcome variables.
The exploratory subgroup analyses performed based on smoking status (smokers versus ex-smokers) and concomitant ICS therapy (ICS versus no ICS) showed that there were no significant differences between subgroups in the main treatment effects for pulmonary function or exercise parameters.

\section{DISCUSSION}

ROF was associated with: 1) no significant changes in static lung hyperinflation or exercise endurance time; 2) progressive improvements in airway function over 12 weeks; 3) small but consistent improvements in ventilation and $\mathrm{Sp}, \mathrm{O}_{2}$ during exercise; and 4) prevention of worsening dynamic lung hyperinflation during exercise that occurred in those randomised to PBO.

Subjects in this study had moderate-to-severe expiratory flow limitation and lung hyperinflation, clinically significant chronic activity-related dyspnoea and a reduced symptom-limited peak $V^{\prime} \mathrm{O}_{2}$ that was $\sim 60 \%$ pred. Both groups were well matched for age, body size, sex, GOLD stage, pulmonary function abnormalities, peak exercise capacity and chronic dyspnoea. In contrast to recent clinical trials on efficacy of ROF, a history of chronic bronchitis, exacerbations and foundational bronchodilator therapy were not specified entry criteria for the current study [1-4]. However, approximately half of our sample had severe COPD by GOLD criteria. 


\begin{tabular}{|c|c|c|c|c|}
\hline \multirow[t]{3}{*}{ TABLE 3} & \multicolumn{4}{|c|}{$\begin{array}{l}\text { Pre-bronchodilator measurements during } \\
\text { symptom-limited continuous work rate exercise } \\
\text { at } 75 \% \text { of the maximum incremental work rate at } \\
\text { the beginning (To) and end (Tlast) of study } \\
\text { treatment in the intention-to-treat analysis }\end{array}$} \\
\hline & & \multirow[t]{2}{*}{ To } & \multicolumn{2}{|c|}{ Tlast } \\
\hline & & & ROF & PBO \\
\hline Exercise time & & 477 & $492 \pm 24$ & $528 \pm 26$ \\
\hline \multicolumn{5}{|c|}{ Peak exercise } \\
\hline Dyspnoea B & org score & 6.6 & $6.5 \pm 0.1$ & $6.8 \pm 0.2$ \\
\hline $\begin{array}{l}\text { Leg discomf } \\
\text { score }\end{array}$ & ort Borg & 4.9 & $5.3 \pm 0.2$ & $5.1 \pm 0.2$ \\
\hline$V^{\prime} \mathrm{O}_{2} L \cdot \mathrm{min}^{-1}$ & & 1.19 & $1.19 \pm 0.02$ & $1.18 \pm 0.02$ \\
\hline$V^{\prime} \mathrm{CO}_{2} \mathrm{~L} \cdot \mathrm{min}^{-1}$ & & 1.16 & $1.16 \pm 0.02$ & $1.15 \pm 0.02$ \\
\hline$V^{\prime} E L \cdot m^{-1}$ & & 41.6 & $43.8 \pm 0.60^{*, \#}$ & $41.9 \pm 0.68$ \\
\hline$f \mathrm{R}$ breaths $\cdot \mathrm{m}$ & & 30.1 & $31.7 \pm 0.43^{*}$ & $30.8 \pm 0.48$ \\
\hline VT L & & 1.44 & $1.43 \pm 0.02$ & $1.41 \pm 0.02$ \\
\hline IC L & & 2.20 & $2.11 \pm 0.04^{*}$ & $2.04 \pm 0.05^{\star}$ \\
\hline $\mathrm{Sp}, \mathrm{O}_{2} \%$ & & 93.9 & $94.4 \pm 0.23^{\star . \#}$ & $93.6 \pm 0.26$ \\
\hline \multicolumn{5}{|c|}{ Isotime exercise } \\
\hline Dyspnoea B & org score & 5.0 & $4.8 \pm 0.2$ & $4.8 \pm 0.3$ \\
\hline $\begin{array}{l}\text { Leg discomf } \\
\text { score }\end{array}$ & ort Borg & 3.8 & $4.2 \pm 0.2$ & $3.8 \pm 0.3$ \\
\hline$V^{\prime} \mathrm{O}_{2} L \cdot \min ^{-1}$ & & 1.16 & $1.13 \pm 0.02$ & $1.13 \pm 0.02$ \\
\hline$V^{\prime} \mathrm{CO}_{2} \mathrm{~L} \cdot \mathrm{min}^{-1}$ & & 1.10 & $1.08 \pm 0.02$ & $1.09 \pm 0.02$ \\
\hline$V^{\prime} E L \cdot m^{-1}$ & & 39.6 & $40.6 \pm 0.62^{\# \cdot \cdot}$ & $39.1 \pm 0.70$ \\
\hline$f R$ breaths $\cdot m$ & & 28.4 & $29.5 \pm 0.43^{*}$ & $28.5 \pm 0.48$ \\
\hline$V T \mathrm{~L}$ & & 1.44 & $1.43 \pm 0.02$ & $1.43 \pm 0.02$ \\
\hline IC L & & 2.20 & $2.17 \pm 0.04^{\#}$ & $2.05 \pm 0.04^{*}$ \\
\hline $\mathrm{Sp}, \mathrm{O}_{2} \%$ & & 94.3 & $94.6 \pm 0.22^{\#}$ & $93.9 \pm 0.25$ \\
\hline
\end{tabular}

Data are presented as least square mean \pm SE. ROF: roflumilast; PBO: placebo; $V^{\prime} \mathrm{O}_{2}$ : oxygen uptake; $V^{\prime} \mathrm{CO}_{2}$ : carbon dioxide production; $V^{\prime} \mathrm{E}$ : minute ventilation; fR: respiratory frequency; $V_{T}$ : tidal volume; IC: inspiratory capacity; $\mathrm{Sp}_{\mathrm{O}} \mathrm{O}_{2}$ : arterial oxygen saturation measured by pulse oximetry. ${ }^{*}: p<0.05$ for within-group Tlast versus To; ${ }^{\#}: \mathrm{p}<0.05$ for ROF versus PBO treatment effect (Tlast minus T0); $\because p=0.08$ within-group (Tlast versus To)

Our results confirm those of previous reports of progressive improvements in the pre-bronchodilator FEV1 (by an average of $84 \mathrm{~mL}$ ) over the first 8 weeks of anti-inflammatory therapy, which was sustained at 12 weeks. There were concurrent small but consistent improvements in the FEV1/FVC ratio and sRaw. The changes in resting airway function were distinctly different from those that occur following bronchodilator therapy $[9,10]$. For example, in this group, FVC improved by an average of $0.3 \mathrm{~L}$ during bronchodilator responsiveness testing, whereas there was no change in pre-bronchodilator FVC following 12 weeks of ROF treatment. In patients with more advanced COPD, the increase in FEV1 after bronchodilator therapy mainly reflects volume (FVC) recruitment secondary to lung deflation (reduced RV) [21, 22]. In contrast, there were no consistent changes in RV, FRC, FVC and IC in those randomised to ROF. In the absence of evidence of lung volume recruitment, the increase in FEV1 associated with ROF points to improvement in airflow rates in the larger central airways and in alveolar units with faster mechanical time constants for emptying.
We found no evidence of enhanced responsiveness to bronchodilatory agents: acute reversibility to short-acting $\beta_{2}$-agonist therapy was unchanged after 12 weeks of treatment with ROF. This is consistent with the results of previous studies that have shown that the addition of ROF treatment to patients receiving foundational long-acting bronchodilator medication results in added (but not synergistic) improvements in FEV1 [2]. In this study, it is noteworthy that the improvements in airway function were similar in those receiving ICS maintenance treatment (i.e. $\sim 40 \%$ of the sample) compared to those who were not.

It is conceivable that in patients with advanced COPD, small improvements in airway function of this magnitude are linked to subjective benefits. It is also possible that reduced airway mucosal inflammation per se favourably affects respiratory sensation (via altered sensory afferent inputs from this site) independent of change in respiratory mechanics, as has previously been proposed [23-25]. Dyspnoea intensity ratings at a standardised time during exercise were not decreased in those randomised to ROF versus PBO. However, dyspnoea was selected $15 \%$ less frequently as the primary exercise-limiting symptom in those receiving active medication. Progressive improvements in TDI were seen in those randomised to ROF when compared with baseline, but between-group comparisons were not significant. Other studies have similarly reported small or inconsistent changes in dyspnoea after ROF [1, 2].

The resting IC represents the operating limits for $V \mathrm{~T}$ expansion during exercise in flow-limited patients with COPD and predicts peak ventilation and cycle endurance time [26, 27]. Given the lack of recruitment of resting IC (or decreased lung hyperinflation) with ROF, it is not surprising that endurance time was not increased compared with PBO. During exercise, IC decreased further by an average of $\sim 0.3 \mathrm{~L}$ in each group, reflecting dynamic pulmonary hyperinflation. Dynamic hyperinflation is known to be associated with $V \mathrm{~T}$ restriction, excessive loading and functional weakness of the inspiratory muscles, which collectively contribute to respiratory discomfort and exercise intolerance $[26,27]$. Bronchodilator therapy is associated with increased resting and exercise IC (by 0.2-0.3 L) with a consequent delay in the onset of critical mechanical constraints and intolerable dyspnoea. Although resting IC was unchanged with ROF, dynamic IC was consistently greater during exercise compared with $\mathrm{PBO}$ by an average of $0.12 \mathrm{~L}$, but was not accompanied by any increase in exercise $V \mathrm{~T}$. In this study, treatment with ROF appears to have prevented the worsening of air trapping that occurred after 12 weeks of PBO. Small concurrent increases in exercise minute ventilation $\left(V^{\prime} \mathrm{E}\right)\left(\right.$ of $\left.\leqslant 2 \mathrm{~L} \cdot \mathrm{min}^{-1}\right)$ were also noted with ROF treatment, mainly reflecting the increased $f R$ (of $<2$ breaths per $\mathrm{min}$ ).

Arterial oxygen saturation during exercise progressively improved from week 4 to week 12 in those randomised to ROF: at week 12 , isotime $\mathrm{Sp}, \mathrm{O}_{2}$ increased by $0.7 \%$ compared with $\mathrm{PBO}$. The mechanism(s) of this novel finding are uncertain but point to improvements in ventilation-perfusion relationships during exercise. Improvement in $\mathrm{Sp}, \mathrm{O}_{2}$ was not explained by the increased $V^{\prime} \mathrm{E}$ with ROF, as differences in $\mathrm{Sp}_{\mathrm{p}} \mathrm{O}_{2}$ persisted after accounting for these small differences in $V^{\prime} \mathrm{E}$. There was no evidence for improved efficiency of carbon dioxide production $\left(V^{\prime} \mathrm{CO}_{2}\right)$ as assessed by $V^{\prime} \mathrm{E} / V^{\prime} \mathrm{CO}_{2}$ slopes during exercise. It is noteworthy that similar improvements in $\mathrm{Sp}_{\mathrm{p}} \mathrm{O}_{2}$ have previously 

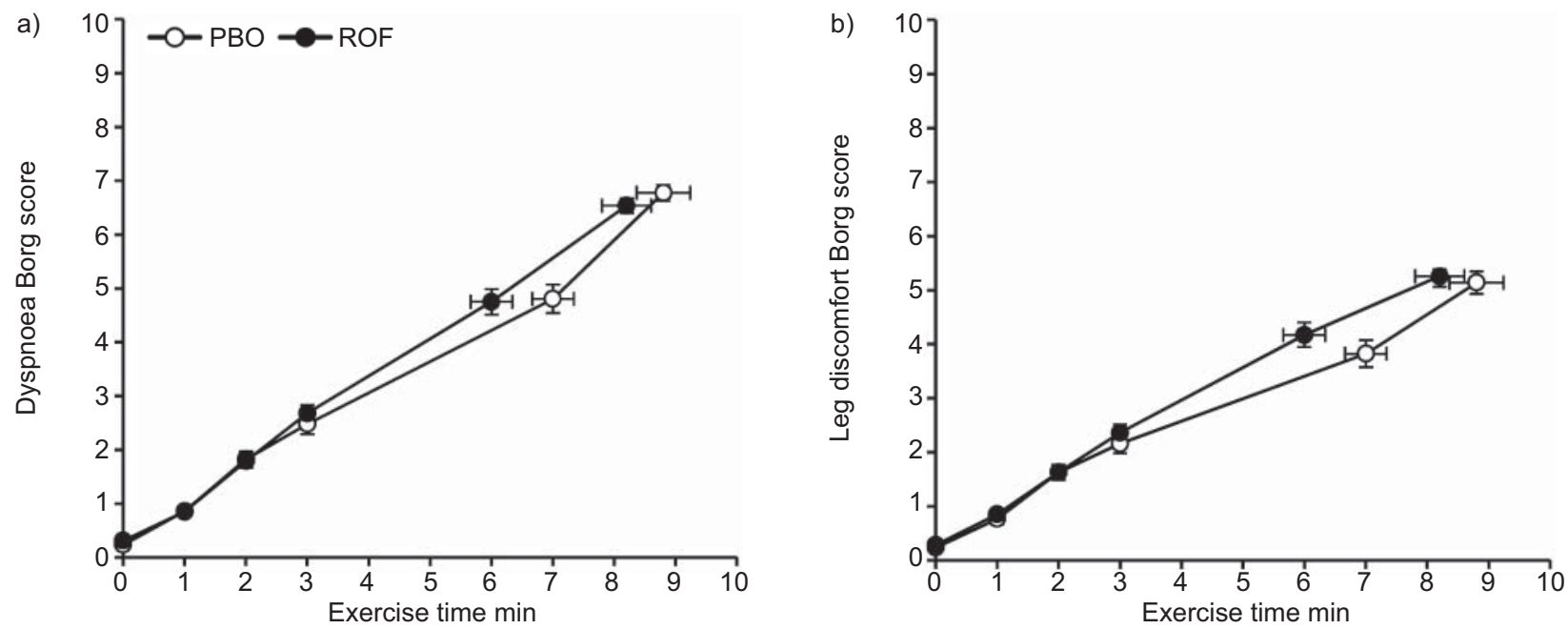

FIGURE 2. Intensity ratings of dyspnoea and leg discomfort during constant work rate exercise at the end-point visit (Tlast) are shown for the roflumilast (ROF) and placebo (PBO) treatment groups. There were no significant treatment differences. Data are presented as least square mean \pm SE for all subjects with paired pre-treatment and Tlast test results and for time-points (i.e. rest, each minute, isotime and peak) with $\geqslant 90 \%$ of the sample contributing to the mean.

been reported during exercise following ICS therapy in asthma and were independent of change in pulmonary function [11]. It is therefore possible, but unproven, that anti-inflammatory effects in peripheral airways and the adjacent pulmonary vascular bed may occur in COPD following systemic ROF therapy [28]. Treatment effects on $\mathrm{Sp}, \mathrm{O}_{2}$ may be better uncovered using treadmill exercise, which, in COPD, results in greater arterial oxygen desaturation than weight-supported cycling [29].
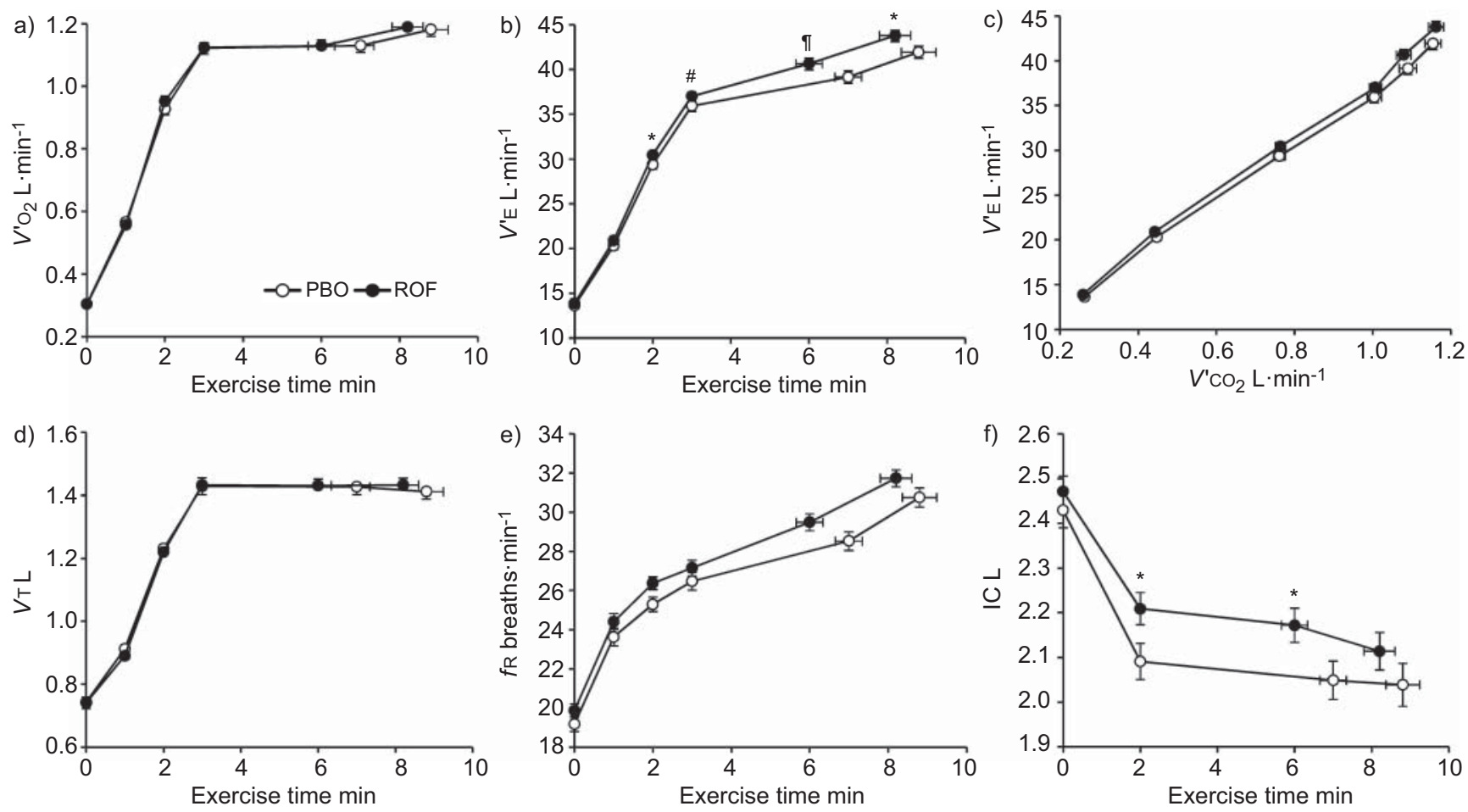

FIGURE 3. Physiological responses to constant work rate exercise at the end-point visit (Tlast) are shown for the roflumilast (ROF) and placebo (PBO) treatment groups. a) Oxygen uptake $\left(V^{\prime} \mathrm{O}_{2}\right)$ versus exercise time; b) minute ventilation $\left(V^{\prime} E\right)$ versus exercise time; c) $V^{\prime} E$ versus carbon dioxide production $\left(V^{\prime} \mathrm{CO}_{2}\right)$; d) tidal volume $\left(V^{2}\right)$ versus exercise time; e) respiratory frequency (fR) versus exercise time; f) inspiratory capacity (IC) versus exercise time. Data are presented as least square mean $\pm S E$ for all subjects with paired pre-treatment (To) and Tlast test results and for time-points (i.e. rest, each minute, isotime and peak) with $\geqslant 90 \%$ of the sample contributing to the mean. *: $p<0.05$ for between-group difference (Tlast minus To) at a selected time-point (i.e. 2-min, isotime or peak); ${ }^{*}: p=0.09$ for between-group difference (Tlast minus To) at a selected timepoint (i.e. 2-min, isotime or peak); ${ }^{\prime}: p=0.05$ for between-group difference (Tlast minus To) at a selected time-point (i.e. 2-min, isotime or peak). 

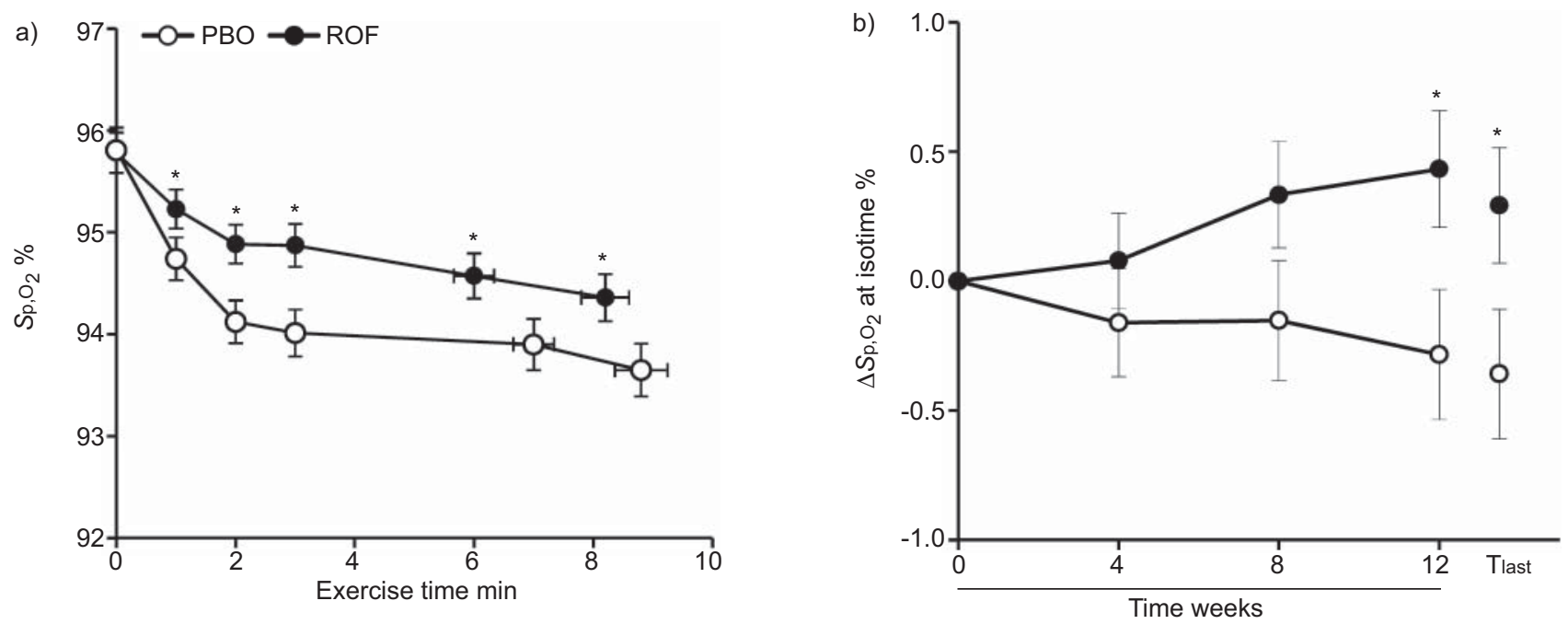

FIGURE 4. a) Arterial oxygen saturation measured by pulse oximetry $\left(\mathrm{Sp}, \mathrm{O}_{2}\right)$ during constant work rate (CWR) exercise at the end-point visit (Tlast) in the roflumilast (ROF) and placebo (PBO) groups. b) Change in $(\Delta) \mathrm{Sp}_{1} \mathrm{O}_{2}$ at isotime, near end-exercise during CWR exercise tests, from the pre-treatment visit (To): the treatment difference at 12 weeks was $0.72 \%(p=0.011)$ and at Tlast was $0.65 \%(p=0.020)$ in favour of ROF. Data are presented as least square mean \pm SE. *: $p<0.05$ for treatment difference (Tlast minus To) at each exercise time-point or treatment visit.

\section{Study limitations}

Inclusion criteria for this study included the presence of lung hyperinflation (FRC $>120 \%$ pred); therefore, the results may not be generalisable to the broader COPD population. However, recent population studies indicate that the majority of patients with moderate-to-severe COPD have resting lung hyperinflation [22]. The physiological effects of ROF described here may be different in the subpopulation of COPD patients for whom the licensing indication exists, i.e. those with chronic bronchitis and a history of exacerbations who receive maintenance bronchodilator therapy.

\section{Conclusion}

This study is the first to examine the physiological effects of ROF during rest and exercise in COPD. The response pattern to this oral anti-inflammatory agent is distinctly different to that of inhaled bronchodilator agents. Thus, small but progressive improvements in airway function were seen in the absence of any improvement in resting lung hyperinflation or in exercise endurance. Newly described non-bronchodilator effects of this medication included small but consistent improvements in air trapping, ventilation and arterial oxyhaemoglobin saturation during exercise. The clinical significance of these short-term physiological improvements in those randomised to ROF remains to be established.

\section{SUPPORT STATEMENT}

The study was funded by Nycomed GmbH (Konstanz, Germany).

\section{STATEMENT OF INTEREST}

Statements of interest for all authors and for the study itself can be found at www.erj.ersjournals.com/site/misc/statements.xhtml

\section{ACKNOWLEDGEMENTS}

The authors wish to thank all investigators, site personnel and subjects who participated in this multicentre study protocol, the INSPIRE study (protocol BY217/M2-118).

\section{REFERENCES}

1 Calverley PM, Rabe KF, Goehring UM, et al. Roflumilast in symptomatic chronic obstructive pulmonary disease: two randomised clinical trials. Lancet 2009; 374: 685-694.

2 Fabbri LM, Calverley PM, Izquierdo-Alonso JL, et al. Roflumilast in moderate-to-severe chronic obstructive pulmonary disease treated with longacting bronchodilators: two randomised clinical trials. Lancet 2009; 374: 695-703.

3 Rennard SI, Calverley PM, Goehring UM, et al. Reduction of exacerbations by the PDE4 inhibitor roflumilast - the importance of defining different subsets of patients with COPD. Respir Res 2011; 12: 18.

4 Calverley PMA, Sanchez-Toril F, McIvor A, et al. Effect of 1-year treatment with roflumilast in severe chronic obstructive pulmonary disease. Am J Respir Crit Care Med 2007; 176: 154-161.

5 Rabe KF, Bateman ED, O'Donnell D, et al. Roflumilast - an oral anti-inflammatory treatment for chronic obstructive pulmonary disease: a randomised controlled trial. Lancet 2005; 366: 563-571.

6 Pauwels RA, Lofdahl C-G, Laitinen LA, et al. Long-term treatment with inhaled budesonide in persons with mild chronic obstructive pulmonary disease who continue smoking. N Engl J Med 1999; 340: 1948-1953.

7 Vestbo J, Sorensen T, Lange $\mathrm{P}$, et al. Long-term effect of inhaled budesonide in mild and moderate chronic obstructive pulmonary disease: a randomised controlled trial. Lancet 1999; 353: 1819-1823.

8 Grootendorst DC, Gauw SA, Baan R, et al. Does a single dose of the phosphodiesterase 4 inhibitor, cilomilast $(15 \mathrm{mg})$, induce bronchodilation in patients with chronic obstructive pulmonary disease? Pulm Pharmacol Ther 2003; 16: 115-120.

9 O'Donnell DE, Flüge T, Gerken F, et al. Effects of tiotropium on lung hyperinflation, dyspnoea and exercise tolerance in COPD. Eur Respir J 2004; 23: 832-840.

10 O'Donnell DE, Voduc N, Fitzpatrick M, et al. Effect of salmeterol on the ventilatory response to exercise in chronic obstructive pulmonary disease. Eur Respir J 2004; 24: 86-94.

11 Haverkamp HC, Dempsey JA, Pegelow, DF., et al. Treatment of airway inflammation improves exercise pulmonary gas exchange and performance in asthmatic subjects. J Allergy Clin Immunol 2007; 120: 39-47. 
12 Pauwels RA, Buist AS, Calverley PMA, et al. Global strategy for the diagnosis, management, and prevention of chronic obstructive pulmonary disease. NHLBI/WHO global initiative for chronic obstructive lung disease (GOLD) workshop summary. Am J Respir Crit Care Med 2001; 163: 1256-1276.

13 Mahler DA, Weinberg DH, Wells CK, et al. The measurement of dyspnea. Contents, interobserver agreement, and physiologic correlates of two new clinical indexes. Chest 1984; 85: 751-758.

14 American Thoracic Society. Standardization of spirometry - 1994 update. Am J Respir Crit Care Med 1995; 152: 1107-1136.

15 Coates AL, Peslin R, Rodenstein D, et al. Measurement of lung volumes by plethysmography. Eur Respir J 1997; 10: 1415-1427.

16 Quanjer PH, Tammeling GJ, Cotes JE, et al. Lung volumes and forced ventilatory flows. Report Working Party Standardization of Lung Function Tests, European Community for Steel and Coal. Official Statement of the European Respiratory Society. Eur Respir J 1993; 6: Suppl. 16, 5-40.

17 Briscoe WA, Dubois AB. The relationship between airway resistance, airway conductance and lung volume in subjects of different age and body size. J Clin Invest 1958; 37: 1279-1285.

18 Cotes JE, Chinn DJ, Quanjer PH, et al. Standardization of the measurement of transfer factor (diffusing capacity). Report Working Party Standardization of Lung Function Tests, European Community for Steel and Coal. Official Statement of the European Respiratory Society. Eur Respir J 1993; 6: Suppl. 16, 41-52.

19 Borg GAV. Psychophysical bases of perceived exertion. Med Sci Sports Exerc 1982; 14: 377-381.

20 Jones NJ. Clinical exercise testing. Philadelphia, WB Saunders Company, 1988; pp. 306-307.
21 Newton MF, O'Donnell DE, Forkert L. Response of lung volumes to inhaled salbutamol in a large population of patients with severe hyperinflation. Chest 2002; 121: 1042-1050.

22 Deesomchok A, Webb KA, Forkert L, et al. Lung hyperinflation and its reversibility in patients with airway obstruction of varying severity. COPD 2010; 7: 428-437.

23 Rosenkranz MA, Busse WW, Johnstone T, et al. Neural circuitry underlying the interaction between emotion and asthma symptom exacerbation. Proc Natl Acad Sci USA 2005; 102: 13319-13324.

24 Mahler DA, Huang S, Tabrizi M, et al. Efficacy and safety of a monoclonal antibody recognizing interleukin-8 in COPD: a pilot study. Chest 2004; 126: 926-934.

25 Ottanelli R, Rosi E, Romagnoli I, et al. Do inhaled corticosteroids affect perception of dyspnea during bronchoconstriction in asthma? Chest 2001; 120: 770-777.

26 O'Donnell DE, Revill SM, Webb KA. Dynamic hyperinflation and exercise intolerance in COPD. Am J Respir Crit Care Med 2001; 164: 770-777.

27 O'Donnell DE, Hamilton AL, Webb KA. Sensory-mechanical relationships during high-intensity, constant-work-rate exercise in COPD. J Appl Physiol 2006; 101: 1025-1035.

28 Izziki M, Raffestin B, Klar J, et al. Effects of roflumilast, a phophodiesterase- 4 inhibitor, on hypoxia- and monocrotalineinduced pulmonary hypertension in rats. J Pharmacol Experimental Therap 2009; 330: 54-62.

29 Hsai D, Casaburi R, Pradhan A, et al. Physiological responses to linear treadmill and cycle ergometer exercise in COPD. Eur Respir J 2009; 34: 605-615. 